\title{
TRACKING THE POLICY LITERACY JOURNEY OF STUDENTS IN A POSTGRADUATE DIPLOMA COURSE IN DISABILITY AND REHABILITATION STUDIES
}

\author{
L. Y. Ned* \\ e-mail: lieketseng@sun.ac.za / http://orcid.org/0000-0001-9844-7828 \\ C. Ohajunwa* \\ e-mail: chioma@sun.ac.za / https://orcid.org/0000-0002-2848-003X
}

R. Luger*

e-mail: rluger@sun.ac.za / https://orcid.org/0000-0002-6902-0435

\section{Geiger* \\ e-mail:mgeiger@sun.ac.za / http://orcid.org/0000-0002-3924-0162}

${ }^{*}$ Centre for Rehabilitation studies

Stellenbosch University

Stellenbosch, South Africa

\section{ABSTRACT}

Health and/or rehabilitation practitioners have to interact with policy decisions. Ideally, they need to be able to understand policies and to engage with them, however, practitioners are often not aware of policies and of how to engage with them. As a post graduate unit with a mandate to develop programmes that respond to practice needs, this article reports on the development of a policy analysis module as part of the Post Graduate Diploma in Disability and Rehabilitation Studies. In this article we report on the development of the module, the approach taken, and on student responses to the module. The course journey of enrolled students is narrated, highlighting the encouragement of student engagement and peer feedback as key to improved learning and understandings in higher education. Facilitators' use of didactic approaches that centre students and participatory learning seem equally important for meaningful learning.

Keywords: policy literacy, student engagement, disability, rehabilitation

\section{INTRODUCTION}

In all spheres of health work, practitioners, whether they are aware of this or not, have to interact with policy decisions. Ideally, they need to be able to understand policies and to engage with them. In low resource contexts in particular, good clinical practice may require practitioners to engage with policy issues. Practitioners may have to use policy-related skills to advocate for 
appropriate services for as great a number of service users as possible. In the South African context, Duncan et al. (2012) and Ned (2013) have shown that health practitioners are often not aware of policies and do not know how to engage with them. Time and resources can be wasted by enthusiastic clinicians trying to develop new programmes which, unbeknown to them, are not in keeping with existing policy guidelines.

Despite the importance of policy issues, students in the health sciences do not generally enter training with a particular interest in policy issues - most of them are far more interested in learning about the mechanics of how to do their work with patients. The question then arises, how best to introduce these students to training in policy literacy and policy engagement.

Writing about issues of disability and health in South Africa, Duncan et al. (2012) report that the most frequently observed and reported way of learning about policy related to healthcare provision is through summary booklets handed out to attendees in meetings. Health professionals and user representatives are expected to read these documents for themselves. This may result in poorly understood concepts and a wide range of interpretations of policies. These authors found that new graduates in the health sciences had minimal exposure to (let alone input on) disability related policies and frameworks during their undergraduate training. Professional staff at district levels had no knowledge or authority to interpret policy at their level of service provision and were seldom given any direction on how to implement disability policies (Duncan et al. 2012). Although there have been changes in the curricula of professionals, practitioners in the field are still reporting that they are not adequately prepared for the challenges related to understanding and implementing disability related policy (Duncan et al. 2012). Empowerment through policy literacy is an increasing need in contexts of service delivery deficiencies and human rights abuses such as those experienced by persons with disabilities in global as well as local southern African contexts (Mji et al. 2013; Prince 2009; Schneider et al. 2013; Stapleton et al. 2006; Switzer and Vaughn 2003).

Policy is a key aspect of context which influences practice across individual, organisational and systems levels. Practice, as a space for policy engagement and implementation, is influenced by how and what people learn about policy (Duncan et al. 2012; Pillay et al. 2016). While there are texts or guides on basic policy analysis methods in other disciplines (Patton, Sawicki and Clark 2015) and even a useful locally developed South African policy analysis framework in rehabilitation studies (Law 2008), a gap remains in terms of what should be taught, and how the development of policy literacy in disability and rehabilitation studies can be supported (Neille and Penn 2015). Policies are constantly changing and being updated to respond to diverse needs and to guide practice and vice versa based on social factors, core concepts of disability and the changing conception of disability (Turnbull, Beegle and 
Stowe 2001; Turnbull and Stowe 2001; Turnbull et al. 2001). As Hess-April (2013) suggests, part of the weakness in knowing, awareness and engagement with the constantly changing policies as well as translating policy to practice can possibly be attributed to a lacking of, or limited, training on policy processes within health science curricula.

Hess-April (2013) also argues that teaching on policy literacy should not merely be a case of orientating students to policies relevant to the field. She calls for addressing policy processes in terms of interpretation of policy and factors influencing analysis, implementation and monitoring. Sixteen years earlier, similar assertions were raised by Pillay, Kathard and Samuels (1997), strengthening the position that policy literacy can act as an enabler for balancing critical reflexivity and an interaction between conceptualisation and actual practice. This allows practitioners to critique both policy and their practice.

With these issues in mind, we embarked on developing a policy analysis module as part of the Post Graduate Diploma in Disability and Rehabilitation Studies. In this article we report on the development of the module, the approach taken, and on student responses to the module.

\section{BACKGROUND TO THE COURSE}

The Postgraduate Diploma in Disability and Rehabilitation is a one-year blended learning programme comprising a non-negotiable two-week contact session and web-based tutorials, discussions and assignments. The programme is of interest to persons who are involved in rehabilitation and disability work at different levels. The approach is interdisciplinary with an emphasis on the development of leadership skills to facilitate development, management, evaluation and research into appropriate and cost-effective rehabilitation and disability-related programmes. Part of the programme outcome is to facilitate lifelong continuing professional development and to develop critical thinkers who can question and appraise models of best practice, theories, policies and phenomena in the field of disability and rehabilitation. In this regard, the programme consists of four course modules, namely: disability and rehabilitation theory and practice; policy analysis in health, disability and rehabilitation; ethical and community constructs; and lastly, community integration of the disabled person.

Through this programme, students begin with theorising disability and rehabilitation and then move to engaging in a process of policy development, analysis and their implementation as informed by how they theorise the key concepts. From there, they critically analyse and evaluate diverse ethics approaches to influence their practice of disability and rehabilitation work, and finally, synthesise everything from previous learning to inform and implement effective community integration. It is intended that the combination of these four course modules strengthens students to become consultants and experts in the field of disability and 
rehabilitation. This study focused on the second course module, which is policy analysis in health, disability and rehabilitation, and its content will be briefly explained later on in this article.

\section{OBJECTIVE}

The objective was to explore the students' journey of policy literacy before, during and after completion of a Post Graduate Diploma in Disability and Rehabilitation Studies.

\section{METHODS}

An exploratory descriptive study design allowed us to track the journey of the post graduate students with regard to policy literacy prior to, during and after engaging with the policy analysis course, and data gathering consisted of three phases.

The first set of data was collected before students started with their two-week contact period for orientation to the course. The students were given prior knowledge questionnaires to complete as part of reflecting about their prior knowledge on policy before coming to the course.

Secondly, the students participated in three different discussion tasks and an assignment as part of their policy analysis course. All three discussion tasks were web-based and concluded with a final assessment, synthesising all their learning in the writing of an authentic learning policy brief for their own environment. The discussions were divided into three key focus areas, namely: policy analysis, policy implementation, and policy monitoring.

All the discussion tasks and final assessment were geared towards facilitating the students' learning through their own self-led meaning making and application of their own professional and/or personal experiences in policy issues. The final assessment emanated from the different discussions they participated in online in the above mentioned three topics of policy analysis. Students were therefore required to identify one issue of interest related to a particular group within the disability sector from the knowledge and incidences presented in the various policy documents, country reports and shadow reports with which they engaged during their online discussions and formative assessments. They then had to create and write a policy brief on this issue of interest, relating it to their work interest. They had to demonstrate careful consideration of involvement of persons with disabilities and respect for cultural sensitivity and diversity relevant to the context of policy implementation/practice. The assignments were analysed thematically as data to show the journey of learning since the first phase.

Thirdly, six months after completion of the course, students were given the opportunity to give written feedback, in response to six open-ended questions asking if and how this course 
had thus far assisted them in their practice and how, if at all, they were using what they had learnt.

All data was thematically analysed by one researcher and reviewed by the three coinvestigators who functioned as a reference group.

Ethics approval for this study was obtained from the Health Research Ethics Committee (Ethics Reference \#: N16/02/025)

\section{Participants}

Data sources included eleven students, enrolled for the postgraduate Diploma in Disability and Rehabilitation Studies in 2016. The participants comprised two students from Lesotho, one from Zambia, one from Zimbabwe and seven students from South Africa (one based in the Gauteng province and six in the Western Cape Province). Of the participants, two were male and nine were female. The group represented diverse professional backgrounds, including one nurse, three psychology/social work/pastoral counsellors, three occupational therapists, one speech therapist, one biokineticist, one physiotherapist and one theologian/pastor/academic. The students were all working while studying part-time with some working in the private sector and others working in government departments; furthermore, some were involved in clinical institution-based work in their disciplines while others were working in non-governmental organisations and at community levels of work. The students were also based in different contexts of work: rural, semi-urban and urban environments respectively.

\section{DEVELOPING THE COURSE - PRINCIPLES, METHODS AND CONTENT}

\section{Course delivery methodology}

The course utilised a blended learning approach within a block release method, where the students first had some contact time in the physical classroom and then the rest of the programme was implemented online. We took a participatory approach within the classroom where practical activities were used to introduce the course and theoretical discussions in the physical classroom to generate discussion and peer engagement with policies. The role of the lecturer was that of a facilitator with students playing an active role and consistently engaged in their own learning. The facilitator introduced the topic and suggested prescribed readings to students aligned to a discussion question. The course was aimed at discussing and interrogating issues of policy processes and analysis though a process of practical strategies and experiential learning.

Concurring with Pillay et al. (1997) in their postulations on policy processes being 
important to consider in training if we are to facilitate transformed practice, we had to think carefully about assisting our students to centre good practice. We considered that giving them more than the content/policy statements contained within these official documents was key in our facilitation of policy literacy (Pillay et al. 1997). To facilitate this centring of good practice, we focused on three components of policy processes: (a) policy analysis; (b) policy implementation; and (c) policy monitoring. This focus built on the suggestions made by Pillay et al. (1997) positing that aspects of how the policy-making process occurs, who the policy makers are, and (of course) what the policies reflect, deserve consideration. In all three components, students had to refer to, reflect on and cite case examples from their practice for contextualised learning in policy literacy.

In this way, practice was also seen as policy (Pillay et al. 1997). Thus, Jansen's (1994) four conceptions of policy specific to curriculum were noteworthy. The first policy concept refers to that which actually happens, where practice is taken as a starting point for policy reflections, thus highlighting the role of the practitioner in the policy-making process. A second concept relates to curriculum policy as political symbolism, where attention is drawn to the political motivations which often drive particular policies. The third concept speaks to how policy may also be perceived as the specification of official intentions. Specific guidelines which the practitioners may follow from the official policy makers are contained here. Finally, the fourth concept considers policy as containing broad guidelines for practice, providing practitioners with general and broad (as opposed to a specific set of) guidelines to utilise. Within each conception of practice, the role of the policy-maker is highlighted. Relative to this is the role of the practitioner, who may be perceived as a recipient of the policy or as an active contributor to the policy-making process (Pillay et al. 1997). Hence Jansen (1995) insists that the power of policies should never be underestimated; nor their role in the practice of any profession in any context thereof.

We briefly give an overview of what was covered under each theme, below.

\section{Policy analysis}

Students started off by reflecting on their previous experiences of policy and unpacked what their relationship to policy had been like, which was then linked to a brief discussion of discourse theory. Here, the learning was dedicated to understanding that every policy document carries a discourse with it, and does not rest in an empty space. It was also highlighted that every policy document has a context to it; right from its statement of purpose and problem identification, it is influenced by a philosophy, is often contested and negotiated and is aimed at certain outcomes, depending on the type of policy. This route to introduce students to policy 
analysis is supported by Hyatt (2013) who pays attention to interrogating how texts and practices are ideologically shaped by relations of power, with the analysis being a tool for speaking back to power. In this approach, discourse construction is used as a central concept to move away from the notion of policy as a product (merely enshrined in a policy text) to one which focuses on policy as a process, involving the production, reification and implementation of policy (Hyatt 2013).

The relevance of understanding voice, text, language, goals, and "the who" of policymaking was emphasised, as the understanding of the context of policy formation is important for understanding and analysing policy. Students were introduced to the different types of policies as well as the steps of policy processes and they identified policies of choice to apply these analysis tools, debating with peers and giving feedback. Then for the web-based discussion task, students were given a contextually relevant local policy document on disability and asked to apply the analysis tools discussed, with their own illustrations of that policy (in terms of aims, discourse, dominant/silenced voices, intended audience, text and sub-text, language used, context of formation and possible negotiations made).

\section{Policy implementation}

From these discussions on personal experience and its link to discourse that influences policy, the students entered the space of implementation. Here students again brought in the personal, contextual and socio-cultural factors, discussing how these affect their implementation as duty bearers. This was important in policy processes to get students to, firstly, pay attention to political, economic, and social constraints that will always impact on the practicalities of policy implementation. Secondly, it was aimed at enabling awareness of the notion of interpretation of social actors as there is always an interpretive element in policy; thus addressing the need for students to take cognisance of the existence of patterns of inequality that continue to play out as they engage with policies in their respective contexts. This was again linked to personal history, knowledge discourses, lack of adequate resources, attitudinal challenges and existing power dynamics often impacting on how policy is interpreted, as well as the regular subjugation of various contexts and cultures in policies. Taking the students through the steps of understanding these policy implementation factors as context dependent, demonstrated the notion of policy as a process, value laden, interactional and multidimensional, often resulting in both intended and unintended consequences (Hyatt 2013; Taylor et al. 1997).

In class during the contact sessions, students were asked to identify policies from their home countries or work contexts and discuss how they would implement these policies successfully taking note of the challenges identified. The outcome of the discussion was to 
acknowledge each person as part of policy processes either through interpretation or through experience of policy; and also, to understand the diversity of spaces for policy implementation and the need for a constant negotiation of the processes. For the web-based discussions, students were asked to identify relevant articles from the United Nations Convention on the Rights of Persons with Disabilities (UNCRPD) (UN 2006) related to their work or personal interest, and to discuss how they could best implement these policy documents within their work or personal community context. First, they had to give an introduction to their context, followed by a discussion of the chosen article and how they would implement it. They had to show how they have taken note of the imbalances that exist within their context, power dynamics, prevalent socio-political and cultural discourses; thus, an intersectoral approach. The use of an intersectional perspective to ensure inclusion of persons with disabilities throughout the process was key.

\section{Policy monitoring}

This last section intended to highlight the relevance of monitoring policies for effective implementation, with monitoring being more effective when done as a collective. Students went through an activity with the same policy documents used for the implementation phase, trying to identify factors that indicate successful and unsuccessful implementation, respectively. These factors were then compared to the intended outcomes of the policy document, highlighting the gaps. Students completed a didactic session on writing a policy brief and then identified one issue related to disability about which they could practice writing a policy brief. For the third online discussion assignment, students had to choose from three sets of country reports and corresponding shadow reports submitted to the United Nations. They read and identified the similarities and differences between the government and shadow reports, highlighting dominant discourses and voice, language, text and various compromises expressed within the policies. The outcomes of the analysis were compared to their own contexts of policy implementation, considering contextually relevant ways to monitor policy implementation across communities of practice.

\section{FINDINGS}

The findings are presented in three sections: firstly, data from the students' responses to the prior knowledge questionnaires; secondly, data relating to what students did and the policy briefs they developed; and thirdly, data representing the students' post-course feedback. 


\section{Before they started: Students not interested in policy engagement}

Seven of the class of eleven reported their awareness of international disability-related policies prior to commencing the course, while eight reported an awareness of disability-related policies in their own countries. When asked about the United Nations Convention on the Rights of Persons with Disabilities (UNCRPD) (UN 2006) specifically, six members of the class reported knowing some of its contents, but none could report that they were very familiar with it or were referring to it to strengthen an argument or a request; or were applying the policy regularly in the workplace; or were involved in the development of this policy. Four of the seven South African students knew that the $U N C R P D$ had been ratified by their government. Two of the four international students (from Lesotho, Zambia and Zimbabwe) knew that their governments had ratified the $U N C R P D$. No other international disability and rehabilitation policies were reported as being known or used.

In terms of the level of awareness / knowledge / application of national disability and rehabilitation policies in South Africa, two of the seven South African students had not heard of any of the three national policies. The remaining five of the seven had heard of, but were unfamiliar with, the content of the Integrated National Disability Strategy (1997) and National Disability Rights Policy (2015). With the apparently most familiar National Rehabilitation Policy (2000) in South Africa, two of the seven South African students knew some of its contents, but none responded that they were able to refer to it to strengthen an argument or a request, or were applying the policy regularly in the workplace or were involved in the development of this policy.

The two students from Lesotho were able to identify that they have a national policy entitled The National Rehabilitation Policy: Mainstreaming People with Disabilities into Society. Furthermore, they reported to be very familiar with the policy, but did not respond that they were referring to it to strengthen an argument or a request, were applying the policy regularly in the workplace or were involved in the development of this policy. The students from Zambia and Zimbabwe did not report knowledge of any national policies from their countries.

Interestingly, throughout the different levels of policy, none of the students indicated being very familiar with the policies (except for the Lesotho students), referring to it in practice or applying it or having been involved in their developments.

When asked about any international or national frameworks they were aware of prior to commencing the Post Graduate Diploma in Disability and Rehabilitation Studies, five of the eleven students did not know of any. Of those mentioned by the remaining six students, only the International Classification of Functioning, Disability and Health (ICF) (2001) was 
mentioned four times and was in fact the only framework to be mentioned more than once. Others mentioned included Health 2030 plan, Millennium Development Goals, and Disability Charter. When asked about any international or national disability guidelines they were aware of, six of the eleven students did not know of any.

Interestingly, of the nine students who responded to an open-ended question about how the awareness and knowledge (or lack thereof) of any of the indicated policies, frameworks and guidelines was influencing their work or career, there was general consensus that a lack of awareness makes one less effective as a rehabilitation professional and that increased knowledge is beneficial for improved service delivery for persons with disabilities. The quotes below show how they thought the awareness (or lack thereof) of policies pertaining to their work, influences their daily work:

"I feel my lack of knowledge could potentially limit the impact of my role as a health professional (Biokineticist) in the broader community, outside of private practice." (Participant 7).

"I am currently not able to fully support the decisions I make regarding employees with disability using relevant policies, frameworks and guidelines as I'm not well versed with them." (Participant $5)$.

"I don't have enough current knowledge, especially relating to the South African context, to allow me to provide my patients with the necessary information regarding long term management outside of my scope of practice as a Speech Therapist." (Participant 2).

"Lack of knowledge w.r.t. policies and frameworks leads to poor planning, referral and lack of resources and service delivery to disabled clients accessing services. Being a rehabilitation practitioner at ground level and having knowledge of policies, guidelines and framework will lead to interdisciplinary as well as intersectoral collaboration leading to maximised community/social integration and social inclusion." (Participant 8).

\section{This is what they produce - The policy brief as an output of the course}

From these discussions, the final assignment on writing a policy brief emanated. Students were required to identify an issue related to their work or research interest from all previous discussions related to a particular target group within the disability sector. They then wrote a policy brief on the issue identified, referring to relevant discussions and academic literature sources, showing careful consideration for involvement of persons with disabilities and respect for cultural sensitivity and diversity relevant to the context of policy implementation/practice.

In their policy briefs written approximately five months later, eight participants (participant 11, 1, 3, 2, 4, 8, 6, 9) demonstrated their familiarity with the contents of the $U N C R P D$ as they were able to quote relevant sections and used it appropriately to strengthen and support their argument in the context of a work setting. Participants 1, 2, 8 utilised the WPRPD, participant 3 utilised Education White Paper 6 on Special Needs Education: Building 
an Inclusive Education and Training System (2001) and participant 8 utilised the National Rehabilitation Policy (NRP 2000), to support their policy brief.

In the Policy Brief the student from Zambia had both learned about and was able to utilise the Zambian Workers' Compensation Act No. 10 of 1999 and PWDs Act No. 6 of 2012, to strengthen their policy brief. Likewise, participant 6 from Lesotho referred to and utilised their Development Goals Status Report (2014), Millennium Development Goals Status Report (2013) and The National Strategic Development Plan 2012/13 - 2016/17 in their policy briefs.

In the policy briefs, Healthcare 2030: The Road to Wellness and Framework and Strategy for Disability and Rehabilitation Services in South Africa 2015-2020 (Republic of South Africa [DoH], nd.), were utilised by participant 4. Participant 8 utilised the South African Guidelines on the Provision of Assistive Devices in SA and participant 11 utilised the Zambian Workers Compensation Board (WCB) of Manitoba (2013).

The topics of the policy briefs showed a significant widening of the students' understanding of rehabilitation with intervention being aimed at the level of participation in that they addressed accessible transport, wheelchair provision and maintenance systems, inclusive education, gainful employment, facilitating informed consent, and empowerment around treatment.

\section{Commentary from the external moderator}

Following these outputs, the external moderator shared the following commentary about the assessment of the students:

"I think that this assignment was a good way of assessing the domain of 'policy analysis' - getting the students to apply their knowledge in very real ways to their own work situation. For me, this ensures that the assessment task becomes a valuable learning experience for the students that they can take back with them into their work situations. It also seemed to me that from the topics chosen by the students and from the way in which they approached the assignment, they had been interested in what was covered in the course and they had developed a good understanding of the issues that were explored." (Extract from the External Moderator report for the Policy Brief Exam, 2016).

\section{Post Diploma questionnaire: How they found the course - Their feedback and the usefulness}

\section{They know and they want to know}

When asked to reflect back on their understanding of policy prior to attending, participants show how they did not know much and did not see the need to know about policy: 
"Policy was very foreign to me ... something that was imposed on me, rather than something that I had a role in shaping. It felt as if I had to (sometimes blindly) implement or follow policy, rather than policy being a tool I could use to advocate alongside my patients." (Participant 2).

“... in my mind policy was something that was developed by 'others' at government level and passed down." (Participant 7).

"I had a very superficial understanding of policy, despite its relevance within the context of my own work. It was something out there whose importance I appreciated but had very little knowledge of what it was, what purpose it served and its nature." (Participant 10).

\section{They see why they should know}

When asked about the shift in their understanding, this is what they shared:

"Yes - as stated in my first answer, my understanding of policies changed dramatically. Policy was something I perceived as being imposed on me, now I know that policy formation is an interactive process that I can help shape. It has also highlighted to me the responsibility I have to be well-versed in what policy states (especially within the areas I work in) so that I can be an advocate for PWDs." (Participant 2).

"Yes! Before I enrolled I had very little interest in policies, as the lack of understanding both the jargon and the process of developing and/or changing policies left me feeling completely removed from it." (Participant 7).

"The more I learnt about policies, the more I realised how important is it to have policies in place for every aspect of life, but even more where working with human beings." (Participant 9).

"There was a shift. It did not matter to me whether there were policies or not. We had this or the other policy in my place of work. It did very little to excite my interest to go through it then. But now I am motivated to lay my hands on any policy that I come across because I am now appreciating better what a policy should look like; types, process etc. I am now familiar with different policies on disability and rehabilitation (national and international) and ways in which they can be constructively appraised." (Participant10).

\section{They show how it helps them}

Additionally, students shared how they have used their policy briefs further in their workplaces:

"I read up on policy more than previously (not as much as I should, yet, but definitely working on it!) and I encourage my patients and their families to know about it as well. I try my best to equip them with the knowledge I have about relevant policies. My assignment related to informed consent in individuals with cognitive and/or communication difficulties; and the knowledge I gained in preparation for the assignment is being incorporated in my nursing and family education on communication with patients." (Participant 2).

"Since attending the course I, and others, have initiated an advocacy team called Advocacy Team for Inclusion (ATI) whose mandate is to advocate for inclusion of students and staff with disabilities in my place of work. As the advocacy team we are working towards the development of a policy document on disability at my place of work. Different key stakeholders have been sensitized; Senior Management, Dean of Student Affairs, Centre for Teaching and Learning, Student Representative Council.” (Participant 10). 
Below we will discuss these findings as related to the journey of the students.

\section{DISCUSSION AND CONCLUSION}

The course enhanced learning through balancing textbook learning with peer engagement while also centring students' everyday doings in their respective workplaces as practical learning opportunities for meaning making. In this course, students were required to reflect about their practices in the workplace as case examples. Their own everyday doings at work were used as learning opportunities. In reflecting about their own experiences, they were further required to read the recommended as well as additional literature to make meaning of their experiences. They would develop a short written piece of their experiences and reflections on literature in response to a discussion topic/question and share it with peers online. The peers would engage the post in the form of either commenting or questioning, which the poster should respond to. As part of learning support, the lecturer acts as a facilitator in this interaction with the role to stimulate thought and dialogue which enables students to liberate their understandings. This interaction stimulated peer-to-peer relationships and lecturer-learner relationships which consequently build conducive learning support that facilitates postgraduate learning. This type of support is good in developing independent questioning learners who have good learning and critical thinking skills and strategies. We also see it as enabling a safe space for learners to interact effectively with peers and lecturers. This learning support equally positions postgraduate education as not just acquisition of facts but the ability to synthesize information in relation to your experiences or contexts as well as ability to put the knowledge to practical use. The above documented shifts in meaning making of policy in relation to their everyday practices is reflective of this.

Almarghani and Mijatovic (2017) posit that encouraging student engagement is highly valuable to improve learning and teaching in higher education. This notion seems key in teaching policy analysis as well. The reflected journey of the students demonstrates the benefits of making space for student engagement with policy and policy analysis. Drawing on their prior experience and knowledge facilitated a shift from the resistance they had against policy to a space of engagement and making meaning of that engagement. From feelings of being a passive bystander in policy to feelings of looking forward to engaging with policy with the aim of questioning, challenging and implementing policy articulations demonstrates such a shift. As Hyatt (2013) affirmed earlier, the challenges of making space for student engagement in policy as relating to the duality of creating both engagement and resistance. In the students' journey, this duality did not materialise; rather through actively including the students and drawing on 
their experiences in critical reflections and/or dialogues with peers, more engagement spaces were opened. Drawing on the students' experiences of their work and diverse contexts served as an invitation for this participatory dialogue that facilitated mind-shift. In this space students took an active role in facilitating their learning.

Additionally, the student engagement and student driven learning was also facilitated by encouraging student participation, teamwork and higher order thinking as core to learning policy processes and generally core in higher education if we are to produce students who are able to engage reflexively and critically as socially responsive practitioners in their respective work spaces to promote disability inclusion. We had to shift from a teacher centred teaching method to a didactic approach that centred students and participatory learning as key in facilitating learning of students about policy processes within the post graduate diploma. One approach that we also believe to have contributed to the student journey was the peer feedback that took place during the online discussions, with the lecturer taking more of a facilitation role in these discussions. Ngar-Fun and Carless (2006) emphasise the potential of peer feedback to enhance student learning in their work in Hong Kong. Though the students did not get involved in allocating marks, this work remains relevant in the context where students enter into dialogue about one another's discussion posts for learning purposes and are assessed for their engagement with each other's work in the form of questions and comments. Peers prompted each other to think more critically in a supportive environment thus enabling better learning.

As Ngar-Fun and Carless (2006) put it, the focus on peer feedback was mainly on interaction with peers as facilitators for improved learning and understandings. This is because students actively participate in articulating evolving understandings with prompt and constant peer feedback throughout the discussions. In this case, the course supported learning with students reflecting and justifying what they have done through the peer feedback process as a facilitator in addition to the presence of a facilitator (lecturer). This is a collaborative approach to learning and we believe that it is important in teaching policy processes. This journey of students demonstrates that such participatory and collaborative learning may influence students to take this learning back to their practice and shift their initially resistant attitudes towards policy. Their outputs (policy briefs) are evidence of this where they become more critical and reflective about their own practice engaging both policy and practice.

Sherry (2016) alludes to the notion of empowered and empowering participation as the missing layer, yet significant for disability and rehabilitation practitioners. Such spaces afford people an opportunity to become agents of their own change (Duncan et al. 2012). This journey suggests that this approach of capacitating practitioners in policy processes translates to a space where practitioners aim to facilitate the same empowering engagement in their places of work 
as indicated by the students' narrative regarding how this journey has helped them (Ned and Lorenzo 2016). As Hess-April (2013) puts it, policy literacy enables engagement in policy processes by practitioners in order for them to share this expertise with persons with disabilities and community members in their countries so that together they can advocate for effective policies to be implemented. Students show that their engagement with policy enabled them to think of ways to bring together policy and practice both at theoretical and reflexivity levels. Such an engagement strengthens the voices of people in policy making, planning and service provision (Sherry 2015; 2016) and acknowledges the goal of policy as an enhancer of personal, family and societal outcomes and a promoter of systems change.

\section{IMPLICATIONS FOR BLENDED LEARNING AND HIGHER EDUCATION}

There is a need to consider use of multiple modes of delivery that complement each other in order to promote learning that better prepares higher education students to practice what they have learnt. These multiple modes are particularly significant in distance learning for adults in order to facilitate student driven learning instead of lecturer driven. The multiple modes are also important for designing an educational experience that encourages and embraces competing ideas in teaching and learning. The study therefore concludes that effectiveness of blended learning in higher education lies in seeing learning as a process of engagement between the course content, the students, prior knowledge and the facilitator. This engagement creates effective learning support for critical thinking and is critical, if we are to produce learners who are questioners, thinkers and writers in higher education.

\section{LIMITATIONS}

This article is merely limited to our analyses of our first pilot cohort; it would be interesting to track the journey of at least three cohort groups to see similarities or differences in results.

\section{DECLARATION OF INTEREST STATEMENT}

The authors declare that they have no potential conflict of interest associated with writing this article.

\section{REFERENCES}

Almarghani, E. M. and I. Mijatovic. 2017. Factors affecting student engagement in HEIs - It is all about good teaching. Teaching in Higher Education 22(8): 940-956. https://doi.org/10.1080/ 13562517.2017.1319808

Duncan, M., K. Sherry, R. Watson and M. Booi. 2012. Rurality, poverty and disability: Strategies for community led action towards poverty alleviation and social inclusion. Towards Carnegie UCT 
Poverty and Inequality Conference. Theme: Capacitating for Change. Department of Health and Rehabilitation Sciences, Faculty of Health Sciences, University of Cape Town.

Hess-April, L. 2013. Occupational therapy graduates' conceptualisation of occupational justice in community service practice in South Africa: A UWC case study. PhD diss., University of Western Cape, Western Cape, South Africa.

Hyatt, D. 2013. The critical policy discourse analysis frame: Helping doctoral students engage with the educational policy analysis. Teaching in Higher Education 18(8): 833-845. doi:10.1080/13562517.2013.795935

Jansen, J. 1994. Standards and other myths: The transformation of universities in South Africa. Paper presented at the Academic Freedom Lecture, University of Natal-Pietermaritzburg, KwaZuluNatal.

Jansen, J. 1995. Pedagogy as policy. Keynote address to the South African Association of Research in Mathematics and Science Education Conference, University of Cape Town, Cape Town.

Law, F. B. 2008. Developing a policy analysis framework to establish level of access and equity embedded in South African health policies for people with disabilities. Master's thesis, Stellenbosch University, Stellenbosch, South Africa.

Mji, G., P. Chappell, S. B. Statham, N. Mlenzana, C. Goliath, C. de Wet and A. Rhoda. 2013. Understanding the current discourse of rehabilitation: With reference to disability models and rehabilitation policies for evaluation research in the South African setting. SA Journal of Physiotherapy 69(2): 4-9. doi:10.4102/sajp.v69i2.22

Ned, L. 2013. A study to explore the capacity of family and service providers to facilitate participation of disabled youth in accessing opportunities in skills development and employment in Cofimvaba, Eastern Cape. Masters diss., University of Cape Town, South Africa.

Ned, L. and T. Lorenzo. 2016, Enhancing public sectors' capacity for inclusive economic participation of disabled youth in rural communities. African Journal of Disability 5(1): 1-11. doi.org/10.4102/ ajod.v5i1.189.

Neille, J., and C. Penn. 2015. Beyond physical access: A qualitative analysis into the barriers to policy implementation and service provision experienced by persons with disabilities living in a rural context. Rural and Remote Health 15(3332). https://www.rrh.org.au/journal/article/3332

Ngar-Fun, L. and D. Carless. 2006. Peer feedback: The learning element of peer assessment. Teaching in Higher Education 11(3): 279-290. doi:10.1080/13562510600680582

Patton, C., D. Sawicki and J. Clark. 2015. Basic methods of policy analysis and planning. Oxon: Routledge.

Pillay, M., J. Bester, R. Blaauw, A. Harper, A. Msindwana, J. Muller and L. Philips. 2016. Allied health professional rural education: Stellenbosch University learners' experiences. African Journal of Health Professions Education 8(2): 169-173. doi:10.7196/AJHPE.2016.v8i2.578

Pillay, M., H. Kathard and M. A. Samuel. 1997. The curriculum of practice: A conceptual framework for speech-language therapy and audiology practice with a black African First Language clientele. South African Journal of Communication Disorders 44: 109-117. http:/hdl.handle.net/ 10520/AJA03798046_363

Prince, M. J. 2009. Absent citizens: Disability politics and policy in Canada. University of Toronto Press.

Republic of South Africa. nd. Framework and strategy for disability and rehabilitation services in South Africa 2015-2020. South Africa: National Department of Health.

Schneider, M., A. H. Eide, M. Amin, M. MacLachlan and M. Mannan. 2013. Inclusion of vulnerable groups in health policies: Regional policies on health priorities in Africa. African Journal of Disability 2(1): 1-9. doi:10.4102/ajod.v2i1.40

Sherry, K. 2015. Disability and rehabilitation: Essential considerations for equitable, accessible and poverty-reducing health care in South Africa. In South African Health Review 2014/2015, 89-100. Durban: Health Systems Trust. 
Sherry, K. 2016. Occupations of citizenship: The missing layer in empowered engagement between rural people with disabilities and primary healthcare workers in South Africa. PhD diss., University of Cape Town, Cape Town South Africa.

Stapleton, D. C., B. L. O’Day, G. A. Livermore and A. J. Imparato. 2006. Dismantling the poverty trap: Disability policy for the twenty-first century. Milbank Quarterly 84(4): 701-732. doi:10.1111/j. 1468-0009.2006.00465.x

Switzer, J. V. and J. Vaughn. 2003. Disabled rights: American disability policy and the fight for equality. Georgetown University Press.

Taylor, S., F. Rizvi, B. Lingard and M. Henry. 1997. Educational policy and the politics of change. London: Routledge.

Turnbull, H. R., G. Beegle and M. J. Stowe. 2001. The core concepts of disability policy affecting families who have children with disabilities. Journal of Disability Policy Studies 12: 133-143.

Turnbull, H. R. and M. J. Stowe. 2001. A taxonomy for organising the core concepts according to their underlying principles. Journal of Disability Policy Studies 12: 177-197. https://doi.org/ $10.1177 / 104420730101200304$

Turnbull, H. R., B. L. Wilcox, M. J. Stowe and G. T. Umbarger. 2001. Matrix of federal statutes and federal and state court decisions reflecting the core concepts of disability policy. Journal of Disability Policy Studies 12(3): 144-176.

United Nations. 2006. United Nations Convention on the rights of persons with disabilities. UN: New York. http://www.un.org/disabilities/documents/convention/convoptprot-e.pdf (Accessed 26 June 2018). 